\title{
Low-UWB Antennas in Vicinity to Human Body
}

\author{
Chaïmaâ Kissi \\ Electronics and Telecommunication \\ Systems Research Group, National \\ School of Applied Sciences (ENSA) \\ Ibn Tofail University \\ Kenitra, Morocco \\ chaimaakissi1@gmail.com
}

Marko Sonkki

Centre for Wireless Communications,

Faculty of Information Technology and

Electrical Engineering

University of Oulu

Oulu, Finland

marko.sonkki@oulu.fi

\author{
Mariella Särestöniemi \\ Centre for Wireless Communications, \\ Faculty of Information Technology and \\ Electrical Engineering \\ University of Oulu \\ Oulu, Finland \\ mariella.sarestoniemi@oulu.fi
}

Sami Myllymäki

Microelectronics Research Unit,

Faculty of Information Technology and Electrical Engineering

University of Oulu

Oulu, Finland

sami.myllymaki@oulu.fi

Carlos Pomalaza Raez

Department of Electrical and Computer

Engineering

Purdue University

Fort Wayne, Indiana 46805, USA

cpomalaz@purdue.edu

\author{
Timo Kumpuniemi \\ Centre for Wireless Communications, \\ Faculty of Information Technology and \\ Electrical Engineering \\ University of Oulu \\ Oulu, Finland \\ Timo.Kumpuniemi@oulu.fi
}

Mohamed Nabil Srifi
Electronics and Telecommunication
Systems Research Group, National
School of Applied Sciences (ENSA)
Ibn Tofail University
Kenitra, Morocco
srifimn@gmail.com

The antenna performance and channel model is assessed in the presence of a human body with simulations and actual measurements.

\section{SimUlation STUDIES} with different antenna body separation distances. The antenna performance is assessed in close proximity to a human body in terms of return loss, impedance matching, directivity, realized gain and efficiencies. The on-body matching results were confirmed by measurement with different real persons. Later, a free-space propagation study was conducted to assess the farfield antenna performance and to serve as a reference for onbody studies. Finally, an on-body propagation study is presented for different antenna positions with different separation distances from the body.

Keywords-BAN, Body Area Networks, High antenna gain, IEEE 802.15.6 standard, small-intestine, Ultra-wide band, Wireless Capsule Endoscopy

\section{INTRODUCTION}

Nowadays, BAN (Body Area Networks) applications attracts increasing attention in the medical research field [1]. Several studies promote the use of Low-UWB range (3.75$4.25 \mathrm{GHz}$ ) for telemetry, diagnosing, sensing, imaging and localization ends [2]. The most interest of this frequency choice relays in the low path loss and high image resolution. This frequency band is defined originally in IEEE 802.15.6 standard for BAN applications [3]. In recent years, this frequency band has been the subject of several published papers dealing with Wireless Capsule Endoscopy (WCE) localization [4]. An accurate localization can be obtained if good directive antennas and suitable localization algorithms are available. Therefore, one of the key elements of the study success is an on-body detailed investigation using real antennas to take into account the antenna performance in close proximity to human body and also to predict the onbody channel propagation behavior [5].

\section{A. Matching results}

The antenna used in these investigations is a Low-UWB cavity-backed antenna presented first time in [6]. The antenna is operating at Low-UWB band defined by BAN part of IEEE 802.15.6 standard. The antenna answers, in free-space, to the definition of Low-UWB band according to IEEE 802.15.6 standard for BAN applications, which consists on a covered bandwidth about $(3.75-4.25 \mathrm{GHz})$ and a center frequency of $4 \mathrm{GHz}$. Moreover the antenna has a high directivity of $7 \mathrm{dBi}$, which promotes its use for WCE localization purposes. The antenna size is $90.8 \mathrm{~mm} \times 85 \mathrm{~mm} \times 39.5 \mathrm{~mm}$ as referred in Fig. 1 (a).

This section is dedicated to the matching investigations of the antenna in vicinity to human body. At this regard, newest male and female voxel CST models (Gustav and Laura 2018) are chosen emulating human body subjects of these studies. The generated results are compared to a multilayer model, serving for reference, averaging the tissue layout and thicknesses $(h)$ of a thin person as described in Figure 1. The multi-layer model is composed of 6 tissues [7] organized as following in Table I.

The simulated reflection coefficient ( $-10 \mathrm{~dB}$ matching) and the input impedance of the studied Low-UWB antenna are shown in Fig. 2 (a) and (b), respectively. The summarized drawn conclusions are grouped in Table II. The input impedance for $30 \mathrm{~mm}$ separation distance is independent of the model gender and further close to freespace results. Whereas when decreasing the distance " $d$ " to $4 \mathrm{~mm}$, the difference started to be noticed between genders. 
TABLE I: DIELECTRIC PROPERTIES OF THE TISSUES

\begin{tabular}{|c|c|c|c|c|}
\hline Tissue & $\varepsilon_{r}$ & $\begin{array}{c}\sigma \\
{[\mathrm{S} / \mathrm{m}]}\end{array}$ & $\mathrm{h}[\mathrm{mm}]$ & $\begin{array}{c}\rho \\
{\left[\mathrm{kg} / \mathrm{m}^{3}\right]}\end{array}$ \\
\hline Skin & 40.85 & 2.701 & 1.4 & 1100 \\
\hline Fat & 5.125 & 0.1829 & 27 & 910 \\
\hline Muscle & 50.82 & 3.015 & 12 & 1041 \\
\hline SI wall & 50.82 & 3.015 & 1 & 1020 \\
\hline $\begin{array}{c}\text { SI } \\
\text { content }\end{array}$ & 51.63 & 4.622 & 20 & 1020 \\
\hline
\end{tabular}

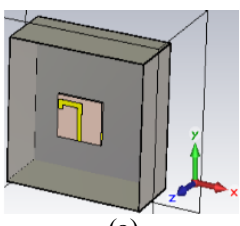

(a)

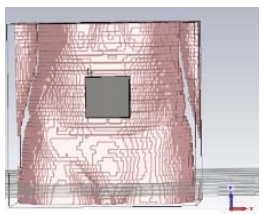

(b)

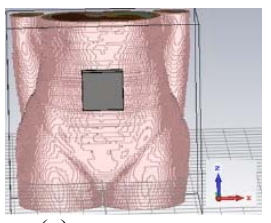

(c)

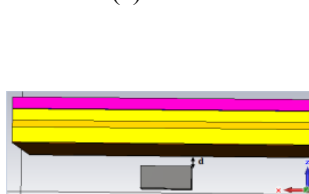

(d)

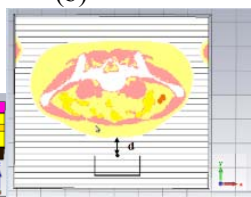

(e)

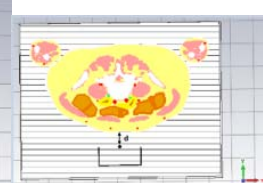

(f)
Fig. 1.(a) Low-UWB antenna structure (b)Front view of the male voxe model (Gustav) and (c) female voxel model (Laura). (d) Side view of the antenna in close proximity to the multi-layered model (e) Cross cuts mentioning the separation distance " $d$ " for Gustav model and (f) Laura model.

To exemplify this, female voxel model showed a bandwidth of $(3.74-4.6 \mathrm{GHz})$ against $(3.85-4.5 \mathrm{GHz})$ for male study case. Interestingly, by further decreasing the separation distance the bandwidth is maintained the same. Furthermore, the antenna has an inductive behavior in proximity to human body. Besides, the antenna resistance is deteriorated at $4 \mathrm{~mm}$ separation distance for both genders (27.66 $\Omega$ for Gustav against $44.41 \Omega$ for Laura). While the opposite is seen at $30 \mathrm{~mm}$ distance $(89.12 \Omega$ for Gustav against $70.65 \Omega$ for Laura) by knowing the antenna matching in free-space fixed to $50 \Omega$.

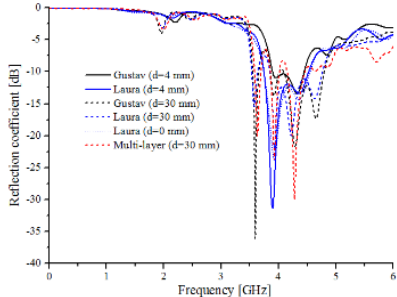

(a)

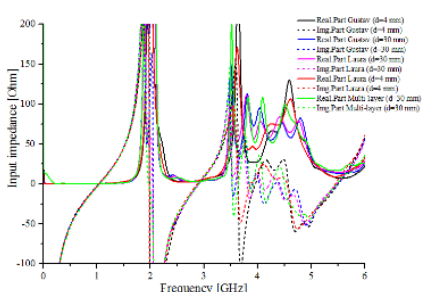

(b)
Fig. 2. (a) Simulated reflection coefficient and (b) input impedance of the Low-UWB antenna at different distances " $d$ " from Gustav and Laura voxel models and multi-layer model serving for reference.

TABLE II: REFLECTION COEFFICIENT COMPARISON OF THE PROPOSED UWB ANTENNA AT DIFFERENT DISTANCES USING DIFFERENT MODELS

\begin{tabular}{|c|c|c|}
\hline Model & $\begin{array}{c}\text { Bandwidth } \\
{[\mathrm{GHz}]}\end{array}$ & $\begin{array}{c}\text { Input impedance } \\
{[\mathrm{Ohm}]}\end{array}$ \\
\hline Gustav $(4 \mathrm{~mm})$ & {$[3.85-4.5]$} & $27.66+\mathrm{j} 8.80$ \\
\hline Gustav $(30 \mathrm{~mm})$ & {$[3.5-4.75]$} & $89.12+\mathrm{j} 10.27$ \\
\hline Laura $(4 \mathrm{~mm})$ & {$[3.74-4.6]$} & $44.41+\mathrm{j} 13.71$ \\
\hline Laura $(30 \mathrm{~mm})$ & {$[3.5-4.75]$} & $70.65+\mathrm{j} 13.29$ \\
\hline $\begin{array}{c}\text { Multi- } \\
\text { layer }(30 \mathrm{~mm})\end{array}$ & {$[3.57-4.45]$} & $62.86+\mathrm{j} 32.88$ \\
\hline
\end{tabular}

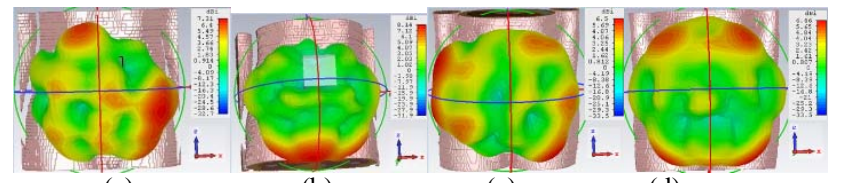

(a)

(b)

(c)

(d)

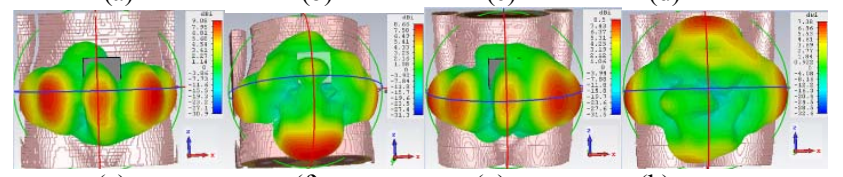

(e)

(f)

(g)

(h)

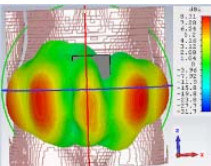

(i)

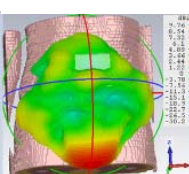

(j)

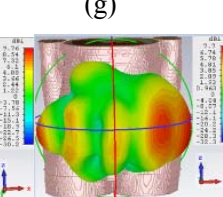

(k)

(1)

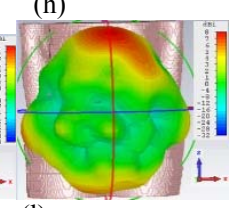

Fig. 3. 3D Directivity of the Low-UWB antenna at $3.75 \mathrm{GHz}$ for (a) $\operatorname{Gustav}(\mathrm{d}=4 \mathrm{~mm})$ (b) $\operatorname{Gustav}(\mathrm{d}=30 \mathrm{~mm}) \quad$ (c) $\operatorname{Laura}(\mathrm{d}=4 \mathrm{~mm}) \quad$ (d) $\operatorname{Laura}(\mathrm{d}=30 \mathrm{~mm})$, at $4 \mathrm{GHz}$ for (e) $\operatorname{Gustav}(\mathrm{d}=4 \mathrm{~mm})(\mathrm{f}) \operatorname{Gustav}(\mathrm{d}=30 \mathrm{~mm})$ (g) $\operatorname{Laura}(\mathrm{d}=4 \mathrm{~mm})$ (h) $\operatorname{Laura}(\mathrm{d}=30 \mathrm{~mm})$ and at $4.25 \mathrm{GHz}$ for (i) $\operatorname{Gustav}(\mathrm{d}=4 \mathrm{~mm}) \quad$ (j) $\operatorname{Gustav}(\mathrm{d}=30 \mathrm{~mm}) \quad(\mathrm{k}) \quad \operatorname{Laura}(\mathrm{d}=4 \mathrm{~mm}) \quad$ (l) Laura $(\mathrm{d}=30 \mathrm{~mm})$

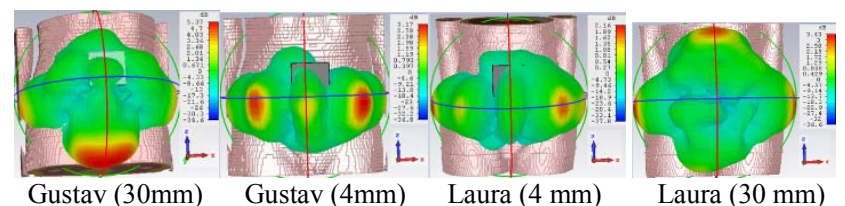

Fig. 4. 3D Realized gain of the Low-UWB antenna at 4 and $30 \mathrm{~mm}$ distances from male and female voxel models at $4 \mathrm{GHz}$.

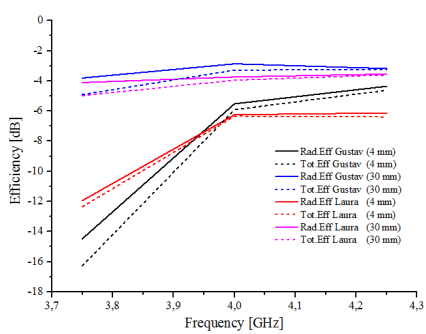

Fig. 5.Simulated radiation and total efficiency of the Low-UWB antenna at different distances "d" from male and female voxel models.

TABLE III: ANTENNA PERFORMANCES AT 4 GHZ IN VICINITY TO MALE AND FEMALE VOXEL MODELS FOR DIFFERENT SEPARATION DISTANCES

\begin{tabular}{|c|c|c|c|c|}
\hline Model & $\begin{array}{c}\text { Rad.Eff } \\
{[\mathrm{dB}]}\end{array}$ & $\begin{array}{c}\text { Tot.Eff } \\
{[\mathrm{dB}]}\end{array}$ & $\begin{array}{c}\text { 3D } \\
\text { Max.Dir } \\
{[\mathrm{dBi}]}\end{array}$ & $\begin{array}{c}\text { 3D } \\
\text { Max.R } \\
\text { Gain } \\
{[\mathrm{dB}]}\end{array}$ \\
\hline Gustav $(4 \mathrm{~mm})$ & -5.52 & -5.91 & 9.08 & 3.17 \\
\hline Gustav $(30 \mathrm{~mm})$ & -2.87 & -3.29 & 8.66 & 5.37 \\
\hline Laura $(4 \mathrm{~mm})$ & -6.24 & -6.34 & 8.5 & 2.16 \\
\hline Laura $(30 \mathrm{~mm})$ & -3.74 & -3.95 & 7.38 & 3.43 \\
\hline
\end{tabular}

An overall insight of the directivity and realized gain orientations of the Low-UWB cavity-backed antenna in close proximity to male and female human bodies for different distances $d$ of $4 \mathrm{~mm}$ and $30 \mathrm{~mm}$ is presented in Fig. 3 and 4, respectively. The antenna performances at $4 \mathrm{GHz}$ in terms of efficiency (radiation and total), 3D maximum directivity and realized gain are grouped in Table III. Results show a high backed directivity from both male and female voxel models at $4 \mathrm{~mm}$ and $30 \mathrm{~mm}$ distance away. Reported high directivities in vicinity to male voxel model (Gustav) at $4 \mathrm{~mm}$ and $30 \mathrm{~mm}$ are $9.08 \mathrm{dBi}$ and $8.66 \mathrm{dBi}$, respectively. The corresponding values close to 
female voxel model (Laura) are $8.5 \mathrm{dBi}$ and $7.38 \mathrm{dBi}$. This means a decrease of $0.42 \mathrm{dBi}$ against $1.12 \mathrm{dBi}$. By counting the tissue losses, it is clearly seen that the realized gain increases with the separation distance increase. To illustrate this, using male body, increasing the distance $d$ from $4 \mathrm{~mm}$ to $30 \mathrm{~mm}$ leads to an increase in the gain. Similarly, using female body, these values are $2.16 \mathrm{~dB}$ and $3.43 \mathrm{~dB}$ corresponding to $4 \mathrm{~mm}$ and $30 \mathrm{~mm}$ distances. The different resolutions of both voxel models has more impact on the presented results, since the resolution of Laura voxel is $1.875 \mathrm{~mm} \times 1.875 \mathrm{~mm} \times 1.25 \mathrm{~mm}$ and Gustav voxel 2.08 $\mathrm{mm} \times 2.08 \mathrm{~mm} \times 2 \mathrm{~mm}$.

The antenna efficiency is proportional to the separation distance from the body as depicted in Figure 5. High efficiency is obtained at $30 \mathrm{~mm}$ compared to $4 \mathrm{~mm}$ separation distance since obviously the close the antenna is to lossy tissues the more antenna efficiency is deteriorated. Further, by increasing the distance $d$, the antenna efficiency will meet the free-space results (efficiency between -7 and $-5 \mathrm{~dB})$. The relation established between the efficiency and the separation distance is mainly due to the reach of the reactive near field area [8].

\section{B. SAR calculations}

The simulated SAR values of the antenna used in this study were assessed by CST SAR calculations appealling to the averaging method IEEE C95.3 [9-10]. The input power set for calculations is $0.00316 \mathrm{~W}$, since the power defined in measurement for VNA calibration is about $5 \mathrm{dBm}$. The tissue volume of the multi-layer used is $4.28 \times 10^{6} \mathrm{~mm}^{3}$. The tissue densities are 1100, 910, 1041 and $1020 \mathrm{~kg} / \mathrm{m}^{3}$ corresponding respectively to skin, fat, muscle and SI (wall and content) as defined by CST voxel models.

The SAR values are calculated for $10 \mathrm{~g}$ averages with antenna-skin distances of 4 and $30 \mathrm{~mm}$ as illustrated in Fig. 6. Table IV mentions the reported SAR related details. The reported SAR values are 0.6 and $0.2 \mathrm{~mW} / \mathrm{kg}$ for $4 \mathrm{~mm}$ and $30 \mathrm{~mm}$, respectively. The absorbed power by the entire volume is less than the allowed (accepted) power defined by IEEE C95.3 standard for $10 \mathrm{~g}$ mass average with different distances. All elements prove the antenna safety in exposure to human body.

\section{MEASUREMENT STUDIES}

\section{A. Matching results}

This sub-section is restricted to the study of the antenna behavior, in terms of $-10 \mathrm{~dB}$ impedance bandwidth covered, in vicinity to human body. Exhaustive investigations will be presented with detailed analysis regarding the measured

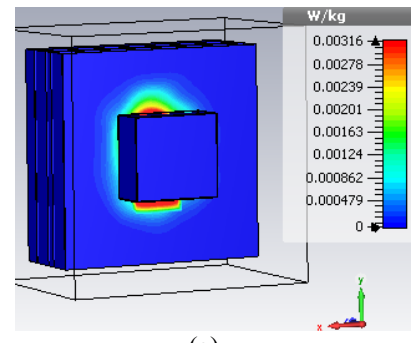

(a)

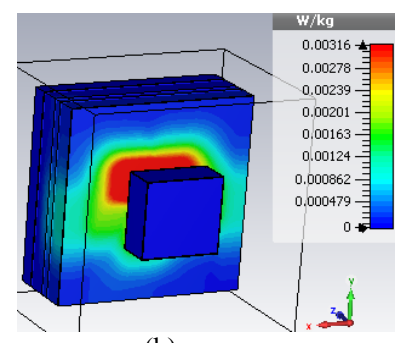

(b)
Fig. 6. SAR values for $10 \mathrm{~g}$ average with different distances d. (a) $10 \mathrm{~g}$ $(\mathrm{d}=4 \mathrm{~mm})(\mathrm{d}) 10 \mathrm{~g}(\mathrm{~d}=30 \mathrm{~mm})$.
TABLE IV: SAR DETAIL VALUES FOR DIFFERENT DISTANCES D

\begin{tabular}{|c|c|c|}
\cline { 2 - 3 } \multicolumn{1}{c|}{} & $10 \mathrm{~g}(4 \mathrm{~mm})$ & $10 \mathrm{~g}(30 \mathrm{~mm})$ \\
\hline $\begin{array}{c}\text { Accepted } \\
\text { Power [W] }\end{array}$ & 0.0030 & 0.0029 \\
\hline $\begin{array}{c}\text { Absorbed } \\
\text { Power [W] }\end{array}$ & 0.0028 & 0.0013 \\
\hline $\begin{array}{c}\text { Tot.SAR } \\
{[\mathrm{W} / \mathrm{kg}]}\end{array}$ & 0.0006 & 0.0002 \\
\hline $\begin{array}{c}\mathrm{Max} \text { SAR } \\
(1 / 10 \mathrm{~g})[\mathrm{W} / \mathrm{kg}]\end{array}$ & 0.1002 & 0.0045 \\
\hline
\end{tabular}

path loss and impulse responses [11] at these studied positions and further cases with more volunteers will be object of other coming papers. Measurements were conducted in an anechoic chamber at University of Oulu to avoid all extra reflections from surrounding objects. Several volunteers were subject of the matching investigations (females and males) with different ages, body shapes and weights. Totally 3 females (F1, F2 and F3) and 4 males (M1, M2, M3 and M4) cases were measured and are presented. The antenna prototypes and the different antenna locations assessed are described in Fig. 7 (a) and (b) by referring to the navel. All volunteers were wearing thin clothes, the antennas were directly held on their belly with black elastic bands. The measured matching results are limited to the following on-body scenarios:

- Symmetric Navel: The antennas are placed in contact and side by side to the navel (A).

- $\quad$ Symmetric - Gap 20 mm: The antennas are placed side by side to the navel and separated with $20 \mathrm{~mm}$ gap.

- $\quad$ Symmetric - Gap $80 \mathrm{~mm}$ : The antennas are placed side by side to the navel and separated with $80 \mathrm{~mm}$ gap.

- Navel - Left Flank: The antenna 2 is placed at the navel and antenna 1 at the left flank (B).

- Navel - Right Flank: The antenna 2 is placed at the navel and antenna 1 at the right flank $(\mathrm{C})$.

The antennas match well in vicinity to real human body for all the volunteers in the different scenarios considered for the study as shown in Figure 8. In other words, the required $-10 \mathrm{~dB}$ bandwidth of [3.75-4.25 GHz] defined for Low-UWB band in IEEE 802.15.6 standard for BAN applications is entirely covered in on-body measurements regardless the volunteer features. However, it is clearly apparent that the antenna bandwidth is enlarged by the body proximity effect.

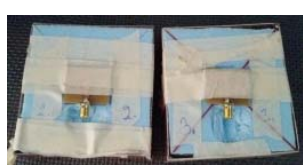

(a)

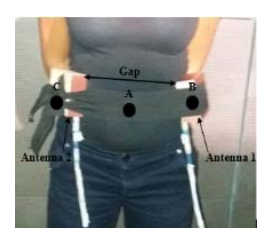

(b)
Fig. 7. (a) The antenna prototypes used in measurements (b) The antenna locations on the human body. 


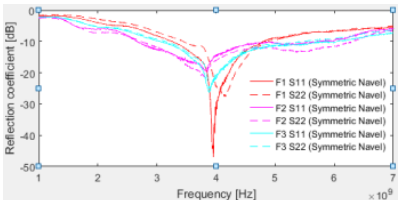

(a)

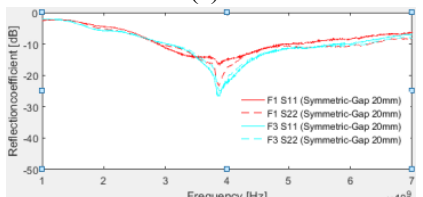

(c)

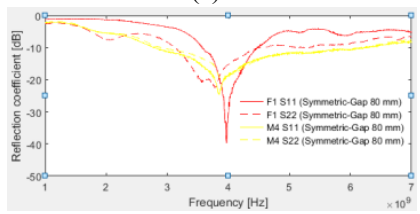

(e)

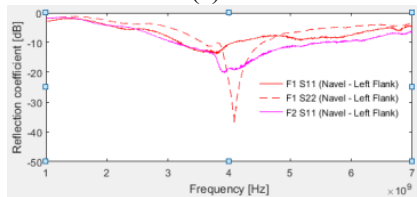

(g)

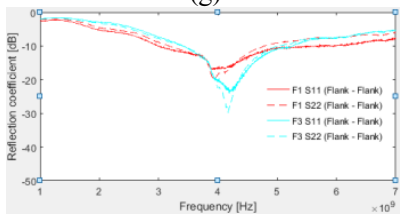

(i)

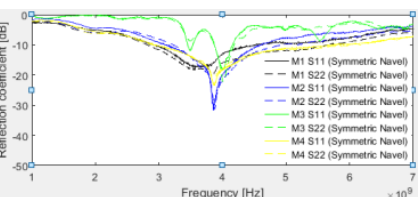

(b)

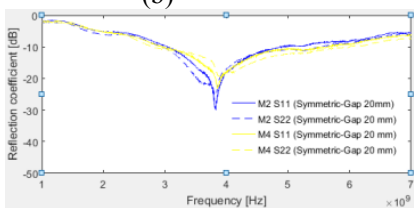

(d)

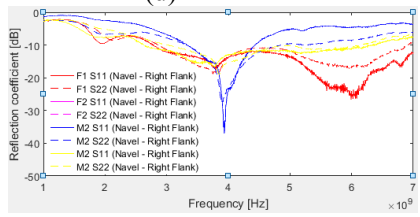

(f)

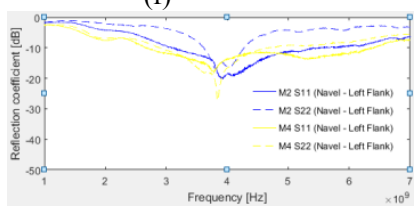

(h)

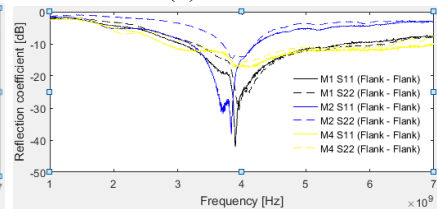

(j)
Fig. 8. Measured reflection coefficient comparison for: "Symmetric Navel" scenario with (a) females and (b) males, "Symmetric-Gap $20 \mathrm{~mm}$ " scenario with (c) females and (d) males, "Symmetric-Gap $80 \mathrm{~mm}$ " and "Navel-Right Flank" scenario with both genders in (e) and (f), "Navel-Left Flank" scenario with (g) and (h), and "Flank-Flank" scenario with (i) females and (j) males.

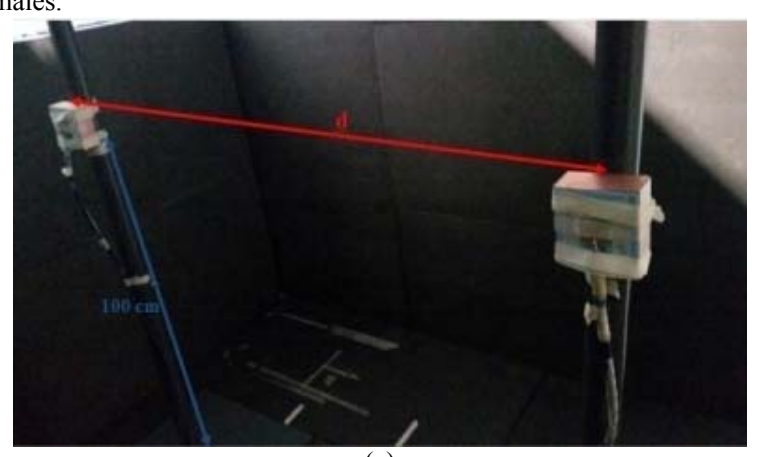

(a)

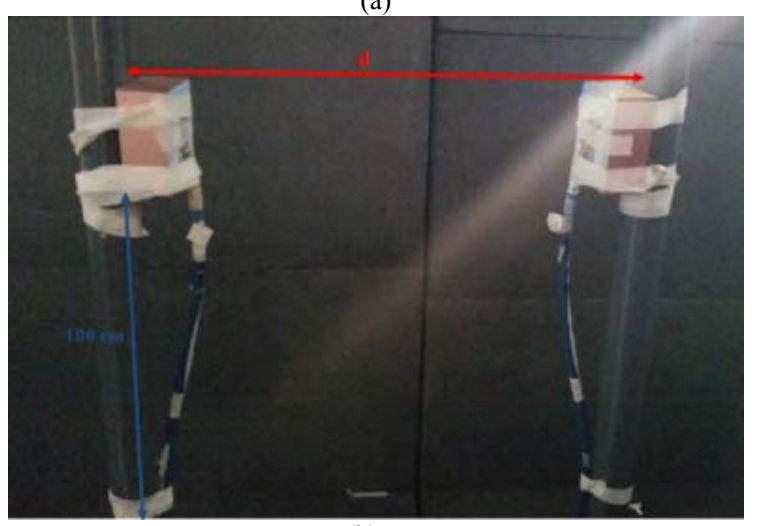

(b)

Fig. 9. Measurement setup for (a) "Side by Side" and (b) "Face to Face" scenarios.

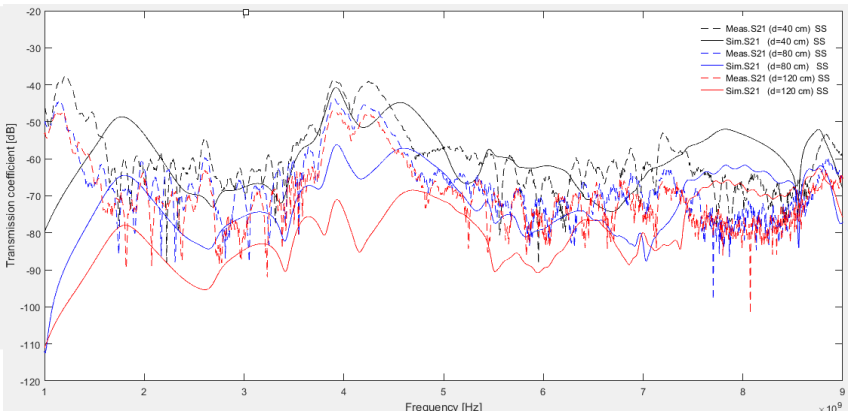

(a)

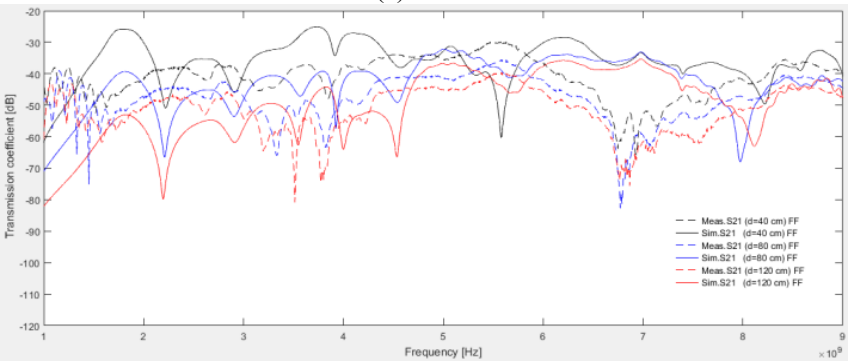

(b)

Fig. 10. Simulated and measured transmission coefficient (S21) in "Side by Side SS" (a) and "Face to Face FF" (b) scenarios, for different antenna separation distances.

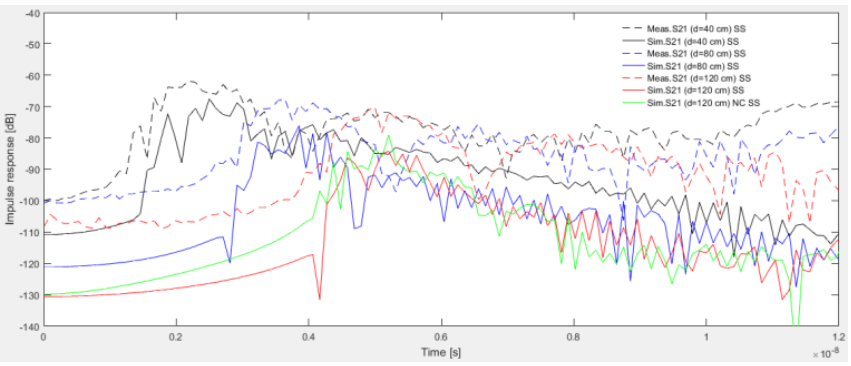

(a)

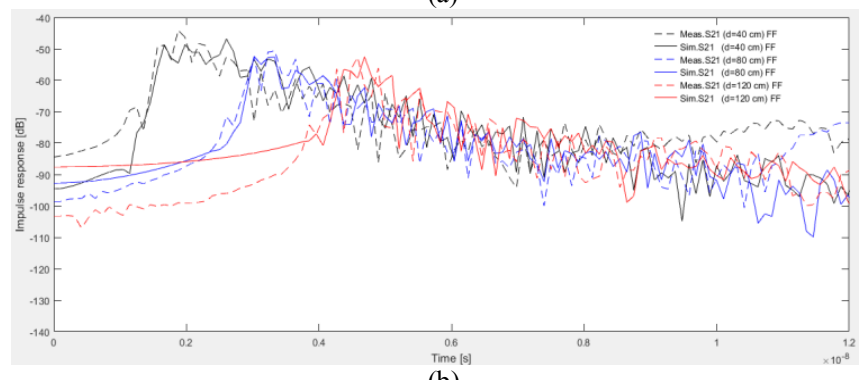

(b)

Fig. 11. Simulated and measured impulse response in "Side by Side SS" (a) and "Face to Face FF" (b) scenarios, for different antenna separation distances.

\section{B. Free-space propagation}

In this subsection a free-space propagation using LowUWB antennas used previously is described in details to assess the far-field antenna radiations. The antennas are not limited to capsule endoscopy localization, but can be widely used for different medical and non-medical applications requiring high directive antennas working at this frequency band of interest. Among the possible medical applications, it is worth noting: wireless respiratory rate monitoring by elaborating a suitable localization algorithm [12-13]. For non-medical applications: 3D localization of wearable antennas in an indoor environment is one option requiring a preliminary study of free-space propagation for antennas used [14-15]. Two different scenarios are studied: "Side by Side" and "Face to Face" where antennas are separated by 
different distances (d) about $40 \mathrm{~cm}, 80 \mathrm{~cm}$ and $120 \mathrm{~cm}$ corresponding to $5.3 \lambda, 10.6 \lambda$, and $16 \lambda$ (where $\lambda$ is the wavelength at the $4 \mathrm{GHz}$ center frequency) as depicted in Fig. 9 (a) and (b). The scenario choice relays basically on providing a reference for on-body studied cases using two antennas. For example, "Side by Side (SS)" case for the onbody position where antennas are placed side by side on the navel (in-contact or with different gap) [11-16] while "Face to Face (FF)" for example for Flank-Flank or Navel-Back scenarios.

A comparison study of the simulated and measured transmission coefficient for FF and SS scenarios is provided in Fig. 10 for different antenna separation distances. For FF scenario, at $4 \mathrm{GHz}$, a measured path loss of around $40 \mathrm{~dB}$, $50 \mathrm{~dB}$ and $57 \mathrm{~dB}$ is reported at $40 \mathrm{~cm}, 80 \mathrm{~cm}$ and $120 \mathrm{~cm}$, respectively. While an averaged measured path loss of $42 \mathrm{~dB}$ is shown for all the separation distances in SS scenario. Regarding the slight mismatch between simulated and measured results, one possible reason is the nonaccurate separation distance used in measurements and reproduced in simulations. It is concluded that the path loss increases with the distance whatever is the antennas dispositions in free-space and it is estimated in the range of [40-57 dB].

The measurement impulse response investigation in FF and SS scenarios for different antenna separation distances is provided by Fig. 11. A good match is clearly seen between simulated and measured results, for FF case, during $12 \mathrm{~ns}$ time delay for all the distances (40,80 and $120 \mathrm{~cm})$. From the results, it is clearly seen the proportional relation between the path loss and signal delay with the antenna separation distance for both scenarios.

\section{On-body propagation}

This on-body study is conducted on two female subjects named F1 and F2. The antennas are held by an elastic band surrounding the belly area. Two on-body scenarios are investigated "Upleft-DownRight" and "Asymmetric Navel" as depicted in Fig. 12. Both females are wearing very thin clothes and a body-antenna separation distance $d$ is considered in these investigations. Parameter $d$ is assumed to be $0 \mathrm{~mm}$ for the case the antennas are placed directly on the clothes. While this value is $30 \mathrm{~mm}$ in case the antennas are separated from clothes by $30 \mathrm{~mm}$-thickness Rohacell pieces.

The transmission coefficient parameter measured for the previously mentionned on-body scenarios using the two female volunteers is presented in Fig. 13. Results show the same path loss value around $24 \mathrm{~dB}$ for both females in "asymmetric Navel" scenario using $30 \mathrm{~mm}$ thickness of Rohacell pieces. This value is increased to $36 \mathrm{~dB}$ for $\mathrm{F} 1$ female volunteer in "Up Left-Down Right" scenario. This enhacement is justified by the body presence (lossy tissues) separating the antennas located on the belly. Furthermore, for the same scenario and volunteer, decreasing the antennabody separation distance to be placed on the clothes $(d=0 \mathrm{~cm})$ lead to a further increase in path loss, estimated around $61 \mathrm{~dB}$, which is evident because the antennas are more close to human tissues and hence antenna radiation is going deep on these latter.

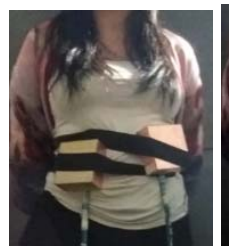

(a)

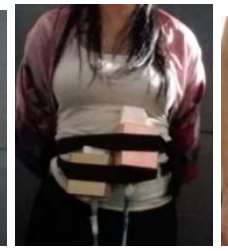

(b)

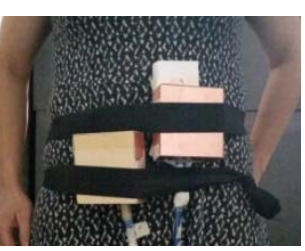

(c)
Fig. 12. Different antenna locations used in on-body measurement for female subjects F1 and F2. "UpLeft-DownRight" scenario for F2 (a). "Asymmetric Navel" scenario for F2 (b) and F1 (c).

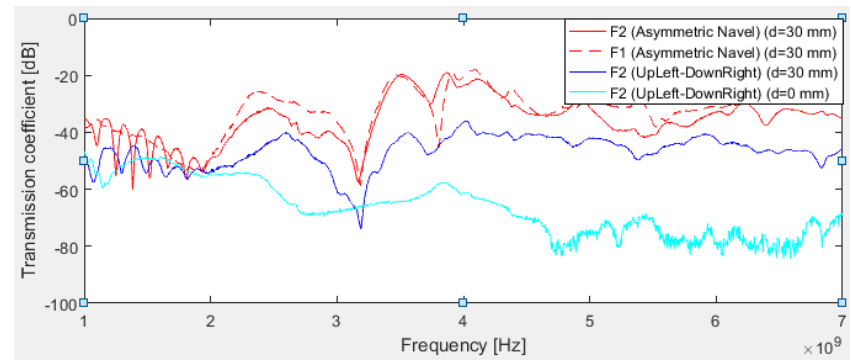

Fig. 13. Measured transmission coefficient for different antenna locations on females F2 and F1.

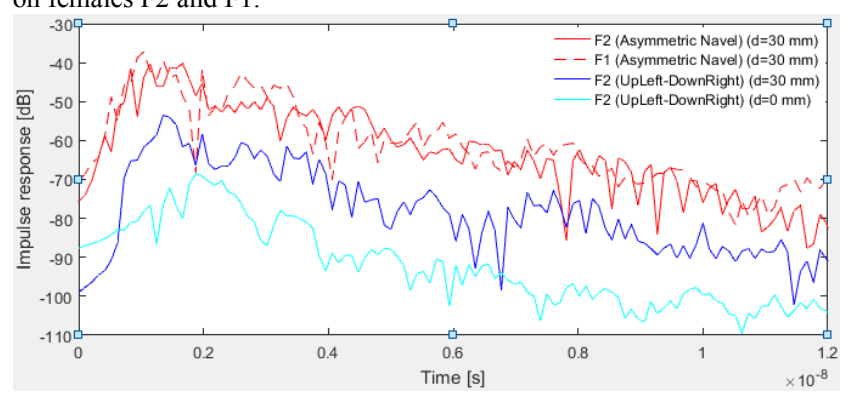

Fig. 14. Measured impulse response for different antenna locations on females F2 and F1.

The measured impulse response for on-body scenarios using the same female volunteers noted F1 and F2, is presented in Fig. 14. It is worth noting the very close impulse response shapes for both volunteers in "Asymmetric Navel" scenario. For F1 and F2 subjects, the first peak occurs at $1.042 \mathrm{~ns}$ and $1.140 \mathrm{~ns}$ respectively, corresponding to power levels of 37.33 and $40.41 \mathrm{~dB}$. While for F2 female, increasing the antenna separating distance, reveals a signal delay of $1.35 \mathrm{~ns}$ with $53.41 \mathrm{~dB}$ reached power level. By eliminating the Rohacell pieces, the antennas are directly in contact to body by means of thin clothes. Then the main signal peak is further delayed to $1.87 \mathrm{~ns}$ with an increased power level about $68.46 \mathrm{~dB}$. All these on-body investigations prove the highly lossy body effect using highly directive antennas working on LowUWB frequency range. A detailed study based on the impact of the skin-antenna distance in time and frequency domains using the same antenna used is presented in [17].

The antenna matching in the different scenarios studied with female subjects in this section is shown in Fig. 15. The antennas have good $-10 \mathrm{~dB}$ matching in close proximity to the body $(d=0 \mathrm{~mm})$ with a bandwidth of [3.13-4.68 $\mathrm{GHz}]$ which meet the requirements of Low-UWB band defined in IEEE 802.15.6 standard for BAN applications. However, increasing the separation distance to $30 \mathrm{~mm}$ conductes to a matching deterioration, and therefore the required bandwidth of $[3.75-4.25 \mathrm{GHz}]$ is covered for $-5 \mathrm{~dB}$ bandwidth about [3.35-4.77 GHz]. 


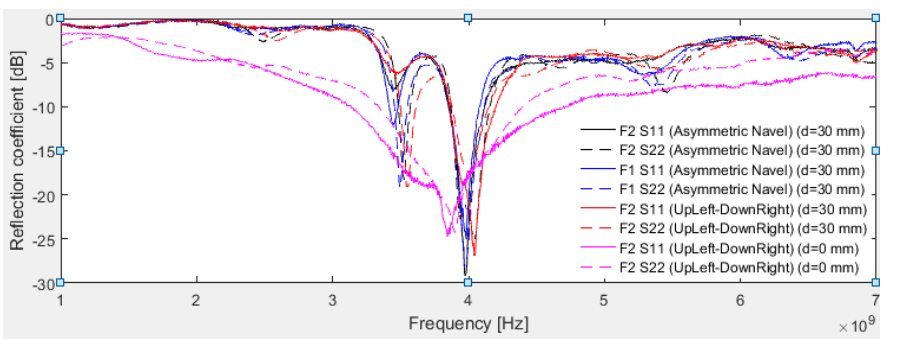

Fig. 15. Measured reflection coefficient in different scenarios at $0 \mathrm{~mm}$ and $30 \mathrm{~mm}$-distances for F2 and F1.

\section{CONCLUSION AND FUTURE WORK}

The paper provides a simulation and measurement based study of Low-UWB antennas used in close proximity to human body and for on-body use. A detailed study appealing to voxel models (Gustav and Laura 2018) is presented to assess the antenna performances in vicinity to male and female bodies. This study was followed by free-space propagation of Low-UWB used antennas. Later, an on-body investigation was conducted of real females to see the body impact on the channel propagation and the path loss. It is concluded that the body generates more path losses besides of the increased signal delays compared to free-space results. This work will be completed by a detailed on-body study for other scenarios like Side-Side (symmetrical to navel), FlankFlank, Navel-Flank, Navel-Back, etc... These simulations will be conducted on different voxel models and validated by measurements for different males and female volunteers of different weight, body shape and age.

\section{ACKNOWLEDGMENT}

Authors would like to thank Professor Jantunen Heli and all in Microelectronics research unit team for the help on antenna design and measurements. Authors would like also to thank all the volunteers who participated in the measurement campaign.

This work was financially supported by ERASMUS+ program, Key 1 - Mobility for learners and staff - for the cooperation between Microelectronics Research Unit and Centre for Wireless Communications, University of Oulu, Finland, and Ibn Tofail University, Electronics and Telecommunication systems research unit, Morocco. The work was partly supported by the Academy of Finland project 6Genesis Flagship (grant no. 318927).

\section{REFERENCES}

[1] A. Pellegrini; A. Brizzi; L. Zhang; K. Ali; Y. Hao; X. Wu; C. C. Constantinou; Y. Nechayev; P. S. Hall; N. Chahat; M. Zhadobov; R. Sauleau, "Antennas and Propagation for Body-Centric Wireless Communications at Millimeter-Wave Frequencies: A Review", IEEE Antennas and Propagation Magazine, Vol. 55, I. 4, pp. $262-$ $287,2013$.

[2] H. Liu; J. Sarrazin; F. Deshours; T. Mavridis; L. Petrillo; Z. Liu ; P. D. Doncker; and A. B-. Delaï, "Performance Assessment of
IR-UWB Body Area Network (BAN) based on IEEE 802.15.6 Standard", IEEE Antennas and Wireless Propagation Letters, Vol. 15, pp. $1645-1648,2016$.

[3] IEEE Standard for Local and metropolitan area networks Part 15.6: Wireless Body Area Networks, pp. IEEE Std 802.15.6-2012, pp. 1 $271,2012$.

[4] K. M. S. Thotahewa; J-. M. Redoutè; M. R. Yuce, "Propagation, Power Absorption, and Temperature Analysis of UWB Wireless Capsule Endoscopy Devices Operating in the Human Body", IEEE Transactions on Microwave Theory and Techniques, Vol. 63, I. 11, pp. $3823-3833,2015$.

[5] P. A. Catherwood and W. G. Scanlon, "The Influence of the User in Body-Centric Antennas and Propagation at 3-6 GHz-A Rician KFactor Approach", IEEE Antennas and Wireless Propagation Letters, Vol. 13, pp. $907-910,2014$.

[6] C. Kissi; M. Särestöniemi; C. P-. Raez; M. Sonkki; and M. N. Srifi, "Low-UWB directive antenna for Wireless Capsule Endoscopy localization", BodyNets2018 conference, Oulu, Finland, October 2018.

[7] https://www.itis.ethz.ch/virtual-population/tissueproperties/database/dielectric-properties/

[8] T. Tuovinen; M. Berg; K. Y. Yazdandoost; J. Iinatti, "Ultra wideband loop antenna on contact with human body tissues", IET Microwaves, Antennas \& Propagation, Vol. 7, I. 7, pp. $588-596$, 2013.

[9] C95.1a-2010 - IEEE Standard for Safety Levels with Respect to Human Exposure to Radio Frequency Electromagnetic Fields, $3 \mathrm{kHz}$ to $300 \mathrm{GHz}$ Amendment 1: Specifies Ceiling Limits for Induced and Contact Current, Clarifies Distinctions between Localized Exposure and Spatial Peak Power Density, IEEE Std C95.1a-2010 (Amendment to IEEE Std C95.1-2005).

[10] C95.2-2018 - IEEE Standard for Radio-Frequency Energy and Current-Flow Symbols, IEEE Std C95.2-2018 (Revision of IEEE Std C95.2-1999)

[11] M. Särestöniemi; C. Kissi;C. P-. Raez; T. Kumpuniemi ;M. Sonkki; S. Myllymäki ; M. Hämäläinen ; and J. Iinatti, "Measurement and simulation based study on the UWB channel characteristics on the abdomen area", accepted to be presented in ISMICT 2019 conference.

[12] Y. Nijsure; W. P. Tay; E. Gunawan; F. Wen; Z. Yang; Y. L. Guan ; and A. P. Chua, "An Impulse Radio Ultrawideband System for Contactless Noninvasive Respiratory Monitoring", IEEE Transactions on Biomedical Engineering, Vol. 60, I. 6, pp. 1509 - 1517, 2013.

[13] J. J. Liu; M-. C. Huang; W. Xu; X. Zhang; L. Stevens ; N. Alshurafa ; and M. Sarrafzadeh, "BreathSens: A Continuous On-Bed Respiratory Monitoring System With Torso Localization Using an Unobtrusive Pressure Sensing Array", IEEE Journal of Biomedical and Health Informatics, Vol.19, I. 5, pp. 1682 - 1688, 2015.

[14] R. Bharadwaj; C. Parini; and A. Alomainy, "Analytical and Experimental Investigations on Ultra Wideband Pulse Width and Shape Effect on the Accuracy of 3D Localization", IEEE Antennas and Wireless Propagation Letters, Vol. 15, pp. 1116 $1119,2016$.

[15] R. Bharadwaj; C. Parini ; and A. Alomainy, "Experimental Investigation of 3D Human Body Localisation Using Wearable Ultra Wideband Antennas", IEEE Transactions on Antennas and Propagation, Vol. 63, I. 11, pp. 5035 - 5044, 2015.

[16] M. Särestöniemi; C. Kissi; C. Pomalaza Raez; M. Sonkki, M. Hämäläinen and J. Iinatti, "Propagation and UWB Channel Characteristics on the Human Abdomen Area," published in EUCAP 2019.

[17] M. Särestöniemi; C. Kissi; C. P-. Raez; M. Hämäläinen; and J. Iinatti, "Impact of the antenna-body distance on the UWB on-body channel characteristics", accepted to be presented in ISMICT 2019 conference. 